\title{
Misoprostol complications in second-trimester termination of pregnancy among women with a history of more than one cesarean section
}

\author{
Marzieh Jamali, MD', Mahmood Bakhtiyari, PhD², Fatemeh Arab, MD³, Masoumeh Mirzamoradi, MD³ \\ ${ }^{1}$ Medical student, School of Medicine, Shahid Beheshti University of Medical Sciences, Tehran; ${ }^{2}$ Department of Community Medicine, Non- \\ communicable Diseases Research Center, Alborz University of Medical Sciences, Karaj; ${ }^{3}$ Department of Obstetrics and Gynecology, Mahdiyeh Hospital, \\ Shahid Beheshti University of Medical Sciences, Tehran, Iran
}

\section{Objective}

This study aims to investigate the complications due to misoprostol administration for second-trimester termination of pregnancy among women with history of 2 or more cesarean scarring.

\section{Methods}

The cohort of this retrospective study included 678 subjects who required second-trimester pregnancy termination, from 2013 to 2015 and treated with vaginal misoprostol of 100 to $400 \mu \mathrm{g}$. The subjects were divided into 3 groups based on their history of cesarean sections: without a history of cesarean section, with a history of one cesarean section, and with a history of more than one cesarean section and uterine scaring.

Results

The results showed that the success rate of misoprostol administration for pregnancy termination was $95.72 \%$. The rate of bleeding as a complication was significantly higher in subjects with a history of more than one cesarean section than in other participants (risk ratio [RR], 2.24; $95 \%$ confidence interval $[\mathrm{Cl}], 1.11-4.0$ ). The incidence of uterine rupture was higher in the group with a history of more than one cesarean section than in other groups. However, no significant difference was observed between the groups ( $R R, 1.44 ; 95 \% \mathrm{Cl}, 0.27-7.6)$. There was a significant relationship between the need for other auxiliary treatments in the pregnancy termination and the history of uterine scarring (RR, 3.3; 95\% Cl, 1.23-9.1).

\section{Conclusion}

The present study showed that pregnancy termination using smaller divided dose of misoprostol in patients with previous history of cesarean scarring may be associated with lower incidence of uterine rupture.

Keywords: Misoprostol; Cesarean section; Pregnancy complications

\section{Introduction}

Second-trimester termination of pregnancy is increasing due to the progress in early diagnosis of fetal abnormalities and maternal life-threatening conditions [1]. In addition, with an increase in the rate of cesarean sections and other uterine surgeries, the number of women with a history of uterine scarring, who require second-trimester termination of pregnancy, is increasing $[2,3]$.

Considering the increase in the number of applicants for pregnancy termination, choosing the most appropriate
Received: 2019.09.28. Revised: 2019.12.15. Accepted: 2019.12.29. Corresponding author: Masoumeh Mirzamoradi, MD Department of Obstetrics and Gynecology, Mahdiyeh Hospital, Shahid Beheshti University of Medical Sciences, Bldg No.2 SBUMS, Arabi Ave, Daneshjoo Blvd, Velenjak, Tehran 19839-63113, Iran E-mail: Drmoradi000@yahoo.com https://orcid.org/0000-0002-6115-3436

Articles published in Obstet Gynecol Sci are open-access, distributed under the terms of the Creative Commons Attribution Non-Commercial License (http://creativecommons. org/licenses/by-nc/3.0/) which permits unrestricted non-commercial use, distribution, and reproduction in any medium, provided the original work is properly cited.

Copyright $\odot 2020$ Korean Society of Obstetrics and Gynecology 


\section{Obstetrics \& Gynecology Science}

Vol. 63, No. 3, 2020

method is one of the most important challenges in women's health science [4]. Different methods have been proposed as options for the second-trimester termination of pregnancy. The medical abortion regimen has been widely used in replacing other methods $[5,6]$. Among the medical treatments, misoprostol is gaining popularity due to its availability and accessibility [7].

Misoprostol is a synthetic prostaglandin E1 analogue, indicated for the prevention of gastric ulcers, for the management of spontaneous abortion and also for inducing abortion $[6,7]$. The administration of this drug is a safe and effective medical method for the second-trimester termination of pregnancy $[6,8]$. Misoprostol acts as an uterotonic agent and causes contraction of uterine smooth muscle and cervical dilation $[8,9]$. However, there are possible complications with its use, such as uterine rupture, coagulation disorders, and severe, abnormal vaginal bleeding. Considerations have also been made regarding misoprostol use and its dosage for second-trimester pregnancy termination in women with previous history of cesarean section $[10,11]$.

Although uterine rupture is a serious complication with misoprostol use and is associated with high mortality and morbidity, there is a relative contraindication for the use of this drug in women with a history of cesarean section $[6,8,11]$. It is still used in many medical centers. Therefore, this study attempts to assess the efficacy of misoprostol in the second-trimester termination of pregnancy, by investigating the complications of its use in women with a history of 2 or more cesarean sections.

\section{Materials and methods}

\section{Patients}

This retrospective cohort study was conducted among 678 subjects, referred to teaching hospitals of the Shahid Beheshti University of Medical Sciences, Tehran, Iran, during 2013-2015, who required a second-trimester termination of pregnancy through treatment with vaginal misoprostol.

The inclusion criteria were as follows: pregnant women in the second trimester with 14 to 24 weeks gestational age determined by ultrasound, and candidates for pregnancy termination due to major fetal abnormalities, fetal death, premature rupture of membranes, and other maternal indications for termination of pregnancy. The exclusion criteria were as follows: multiple pregnancy, women with classic cesarean scarring, known allergies to misoprostol, history of heart or liver disease, use of misoprostol by non-vaginal methods, and incomplete medical records.

\section{Study protocol}

The participants were divided into 3 groups based on their history of cesarean sections: without a history of cesarean section, with a history of one cesarean section and with a history of more than one cesarean sections and uterine scaring (any history of uterine surgery such as cesarean and myomectomy). The divided dose of misoprostol in all cases ranged from 100 to $400 \mu \mathrm{g}$, at intervals of 4 to 6 hours, via vaginal administration [12-14].

A checklist including patient's age, gestational age, divided dose of misoprostol, total dose of misoprostol, duration of induction per hour, number of previous cesarean sections and complications, was completed by the study subjects. The recorded complications included postpartum hemorrhage (>500 mL), need for uterine packing, and hysterectomy.

The primary aim of the current study was to investigate the major complications of using misoprostol (such as hemorrhage, uterine laceration, and hysterectomy) in women with a history of 2 or more cesarean sections and in the second place, to evaluate the success rate of misoprostol use in pregnancy termination.

If 48 hours after the administration of misoprostol at a total dosage of 2,000 $\mu \mathrm{g}$, pregnancy termination was not completed and there was no response to misoprostol, other methods could be used, including high-dose oxytocin induction (50 units oxytocin in $500 \mathrm{~mL}$ of normal saline infused during 3 hours; then 1-hour diuresis; then sequentially escalating in a similar fashion to $150,250,200,250$, and finally 300 units oxytocin, each in $500 \mathrm{~mL}$ normal saline) [15] or using mechanical methods (e.g. hysterotomy) which were to be performed after signed informed consent. In cases of severe hemorrhage [16] (acute uterine bleeding had been described as excessively heavy or prolonged bleeding of uterine origin, sufficient in volume as to require urgent or emergent intervention) and retained placenta, surgical evacuation of the uterus would be considered.

\section{Statistical analysis}

Percentages were calculated for categorical variables, and mean and standard deviation were calculated for continuous 


\section{Obstetrics \& Gynecology Science}

Marzieh Jamali, et al. Misoprostol and maternal complications

variables. Differences between the 2 groups of participants were assessed using independent Student's $t$-tests for continuous variables and chi-square tests for categorical variables. Risk ratio was calculated with $95 \%$ confidence interval to assess the risk of different complications in women with history of more than one cesarean section. Data were initially scrutinized for normality to conform to the assumptions of the applied parametric statistics. To assess the deference's between the mean and the proportion of the studied variables an analysis of variance or Kruskal-Wallis test was used. Further, to investigate the correlation between the 2 continuous variables, Pearson correlation coefficient test was used. The Stata software (version 13MP; StataCorp, College Station, TX, USA) was used to perform all the statistical analyses; $P$-values less than 0.05 were considered statistically significant.

\section{Results}

In this retrospective study, 678 subjects were studied. Out of them, 247 patients had no cesarean section (group 1), 218 patients had a history of one cesarean section (group 2), and 213 patients had a history of 2 or more cesarean sections (group 3). There was no case of placenta previa in this study. The mean age in the studied groups was $26.3 \pm 5.1,28.8 \pm 3.8$ and $28.5 \pm 4.3$ years, respectively. There was no significant difference in gestational age $(P$-value=not significant [NS]) (Table 1).

The mean divided dose of the administered misoprostol in group 1 was $320.6 \pm 98.0 \mu \mathrm{g}$, in participants with one cesarean section was $313.3 \pm 113.0 \mu \mathrm{g}$ and in participants with more than one cesarean section was $208.4 \pm 111.3 \mu \mathrm{g}$. There was a significant relationship between the total doses of misoprostol vaginal administration in the 3 groups. The total dose of misoprostol vaginal administration in the first group was significantly higher than other participants ( $P$-val$\mathrm{ue}<0.001)$. Total dose of misoprostol vaginal administration had a significant negative relationship with gestational age ( $P$-value $<0.001, r=-0.14)$. However, we found no significant correlation between the age of the subject and the total dose of misoprostol ( $P$-value=NS). Out of the total group, 31 subjects had more than $500 \mathrm{~mL}$ of blood loss, and hemorrhage in subjects with more than 1 cesarean section was more than the rest of the cohort. The results showed a significant relationship between hemorrhage as a complication and the history of uterine scarring (RR, 1.56; $P$-value $=0.04)$. Out of the total group, 12 participants had uterine rupture. The results showed that misoprostol was associated with hemorrhage and uterine rupture $(P$-value $=0.04)$. However, there was no significant relationship between uterine rupture and the history of uterine scarring ( $P$-value=NS) (Table 2 ).

The mean induction period in the group, that did not have uterine rupture, was $31.05 \pm 11.60$ hours. The mean induction period in the group with uterine rupture was $30.00 \pm 9.83$ hours. The mean induction period was not significantly different in the 2 groups ( $P$-value=NS).

In addition, $95.7 \%$ of misoprostol cases did not require an auxiliary treatment and only 29 patients needed an auxiliary method, of whom 22 patients were participants with more than one cesarean section $(P$-value<0.001). Despite the induction of abortion through misoprostol and other auxiliary methods, 157 participants required curettage for the removal of fetal remains, of whom non-cesarean participants signifi-

Table 1. Demographic characteristics of patients

\begin{tabular}{|c|c|c|c|c|}
\hline Variables & Group $1(n=247)$ & Group $2(n=218)$ & Group $3(n=213)$ & $P$-value \\
\hline Age (yr) & $26.3 \pm 5.1$ & $28.8 \pm 3.8$ & $28.4 \pm 4.3$ & $<0.001$ \\
\hline Gestational age (wk) & $19.1 \pm 2.8$ & $18.9 \pm 2.8$ & $19.1 \pm 3.3$ & NS \\
\hline Divided dose of misoprostol $(\mu \mathrm{g})$ & $320.6 \pm 98.0$ & $313.3 \pm 113.0$ & $208.4 \pm 111.3$ & $<0.001$ \\
\hline Total dose of misoprostol $(\mu \mathrm{g})$ & $1,585.4 \pm 229.1$ & $1,508.3 \pm 264.0$ & $1,012.7 \pm 351.1$ & $<0.001$ \\
\hline Induction time (hr) & $38.3 \pm 11.2$ & $29.4 \pm 8.7$ & $24.4 \pm 9.9$ & $<0.001$ \\
\hline Divided dose of uterine rupture & $133.3 \pm 33.3$ & $150.0 \pm 2.9$ & $266.6 \pm 66.6$ & 0.001 \\
\hline Total dose of uterine rupture & $1,533.3 \pm 176.4$ & $1,000.0 \pm 216.0$ & $1,266.7 \pm 290.6$ & 0.001 \\
\hline
\end{tabular}

Data are shown as mean \pm standard deviation.

NS, not significant. 


\title{
Obstetrics \& Gynecology Science
}

\author{
Vol. 63 , No. 3, 2020
}

cantly needed curettage more than others $(P$-value $<0.001)$. However, there was no significant difference between groups 2 and 3 regarding the need for curettage ( $P$-value=NS). The results showed that 5 participants needed hysterectomy to be performed: 1 patient from group 1, 2 patients from group 2 and 2 patients from group 3 . There was no statistically significant difference between the 3 groups in terms of hysterectomy ( $P$-value=NS). However, there was statistically significant difference between subjects with or without hysterectomy, in terms of divided or total dose of misoprostol $(P$-value $<0.001)$ (Fig. 1).

\section{Discussion}

While surgical abortion is safe when done appropriately [17], many women select medical abortion, especially those at a younger age [18]. Misoprostol is a prostaglandin E1 analogue that has been primarily used for the treatment and prevention of gastric ulcer disease $[6,19,20]$. However, misoprostol has been also used as an abortion-inducing agent $[19,21]$.

Various studies have explored the effects of misoprostol on the induction of spontaneous termination of pregnancy, which indicates the positive effects of this drug. However, the use of this drug is always accompanied by complications $[19,21]$. Few studies, though, have examined the effects of the medication on labor induction in women with a history of cesarean section and uterine scarring. Studies have shown that the main complications of using misoprostol in women with previous history of cesarean section include uterine rupture, need for blood transfusion, retained placenta and surgical evacuation of the uterus, lack of response to treatment and the need for auxiliary treatment for pregnancy termination and hysterectomy. Among these complications, uterine rupture is the most dangerous and serious complication $[14,22,23]$.

In this retrospective cohort study, we found that medical termination of pregnancy using vaginal misoprostol alone was $95.72 \%$ effective in women with 14-24 weeks gestational age. Zikopoulos et al. [19] study showed that medical termination of pregnancy, using misoprostol alone, was $96 \%$ effective.

The results of current study showed that the mean divided dose of misoprostol in patients with more than once cesarean section was significantly lower than doses in the other 2 groups. Furthermore, the mean total dose of misoprostol was the highest in group 1 and was also the lowest in subjects group 3. In addition, the induction time in group 3 was lower than in the rest of the subjects. The results of our study showed that there is no significant relationship between



Fig. 1. Total and divided misoprostol dosage among the different groups in this study.

Table 2. Frequency and risk of clinical complications in studied subjects

\begin{tabular}{lcccc}
\hline Variables & Group 1 ( $\mathbf{n} \mathbf{2 4 7 )}$ & Group 2 (n=218) & Group 3 (n=213) & ARR $\left.^{\mathbf{a})} \mathbf{( 9 5 \%} \mathbf{C I}\right)$ \\
\hline Bleeding & $8(3.2)$ & $7(3.2)$ & $16(7.5)$ & $2.24(1.11-4)$ \\
Blood transfusion & $8(3.2)$ & $7(3.2)$ & $8(3.8)$ & $1.14(0.91-2.1)$ \\
Uterine rupture & $2(0.8)$ & $3(1.4)$ & $7(3.3)$ & $1.44(0.27-7.6)$ \\
Hysterectomy & $1(0.4)$ & $2(0.9)$ & $2(0.9)$ & $1.0(0.8-1.1)$ \\
Auxiliary method & 0 & $7(3.2)$ & $22(10.3)$ & $3.3(1.23-9.1)$ \\
Curettage & $58(23.5)$ & $51(23.4)$ & $48(22.5)$ & $0.98(0.87-3.26)$ \\
Total & $77(31.2)$ & $77(35.3)$ & $87(40.8)$ & -
\end{tabular}

Values are presented as number (\%).

ARR, adjusted relative risk; $\mathrm{Cl}$, confidence interval.

a)The reference group is comprised of women with history of one or without a history of cesarean section, adjusted for age, divided dose and total dose of Misoprostol, induction time, parity and maternal body mass index. 


\section{Obstetrics \& Gynecology Science}

Marzieh Jamali, et al. Misoprostol and maternal complications

uterine rupture and induction period.

Karaçor et al.'s findings [24], which were in line with our study, indicated that the total dose of misoprostol was lower for pregnancy termination in women with history of previous uterine scarring. Statistical analysis showed that there was a significant relationship between bleeding complications and history of uterine scarring. The chance of hemorrhage as a complication was greater for women with a history of more than 1 cesarean sections. They also concluded in their study that induction that lasted more than 24 hours might be associated with the risk of uterine rupture [24].

The results also showed that $4.57 \%$ of the subjects of the study lost more than $500 \mathrm{~mL}$ of blood during the pregnancy termination and $3.4 \%$ of them needed blood transfusion. Statistical analysis showed that there is a significant relationship between hemorrhage complications and history of uterine scarring. The chance of hemorrhage was higher in women with history of more than one cesarean section.

Daskalakis et al.'s study [13] reveals that delivery in patients with previous cesarean section has a $0.4 \%$ chance of rupture, and this probability increased if misoprostol was used in delivery induction, with or without oxytocin. The results of our study showed that the prevalence of uterine rupture in the subject group was $1.77 \%$, thus indicating that the effect was due to misoprostol use. Considering the fact that there was no significant difference between the 3 groups in terms of uterine rupture, it was higher among patients with a history of more than one cesarean section. Dickinson and Evans [25] reported that patients with previous cesarean section had an increased risk of uterine rupture with misoprostol use. However, Iftikhar and Burney [26] reported no complications such as uterine rupture, major hemorrhage, or shock to be observed after the use of misoprostol in women with a history of one or more cesarean sections. They concluded that there were no contraindications and that misoprostol use is safe and effective [26]. Further, Naguib et al.'s findings [23] confirmed our study's conclusions.

Our results also showed that the rate of using auxiliary methods such as high dose oxytocin induction, mechanical methods, or hysterotomy for pregnancy termination was $4.28 \%$ and was significantly higher in group 3 than in other groups. It seems that uterine scarring reduces the response of uterine receptors to misoprostol and increases the need for additional approaches in pregnancy termination. In addition, $23.1 \%$ of the study subjects required curettage for the removal of fetal remains due to retained placenta or hemorrhage. The results showed that the need for curettage was significantly higher in participants without cesarean section than in those with a history of cesarean section. However, there was no significant difference between participants with one cesarean section and more than one cesarean section.

These contradictions in the results of different studies can be related to ethnic differences as well as differences in the study sample size. Therefore, further studies are required for establishing reliable results. However, it can be argued that drugs with such complications should be used with caution and careful monitoring.

The present study showed that misoprostol use in pregnancy termination did not increase the incidence of uterine rupture in patients with previous history of cesarean scarring. The major complication of misoprostol administration was hemorrhage in the groups with previous cesarean section. In addition, the rate of using auxiliary methods in the pregnancy termination was higher in groups with history of previous cesarean section.

The fact that we did not perform routine curettage or manual uterine vacuity verification after abortion, might be highlighted as a strength of our study. Indications were directed towards placental examination and blood loss evaluation. Moreover, the relatively large sample size of our study, allowed researchers to compare the different outcomes between the 3 groups (without a history of cesarean, with a history of one, and those with 2 or more cesarean sections).

The limitations of this study were related to the retrospective data gathering; therefore, the risk of information bias, such as measurement and misclassification, should be considered. It was assumed that the local regimens of Misoprostol were administered as recorded, but it is possible that some participants received additional medication, although this is unlikely. Uterine scar complications might have been missed if clinical manifestation were not found in the participants. Also, as the dosage of Misoprostol used in each group was different, it should be considered as a limitation of the current study.

The present study showed that termination of pregnancy by less divided dose of misoprostol in patients with previous history of cesarean scarring may be associated with lower uterine rupture. However, considering the incidence of uterine rupture in the group with a history of cesarean section, caution must be exercised. 


\section{Obstetrics \& Gynecology Science}

Vol. 63, No. 3, 2020

\section{Conflict of interest}

No potential conflict of interest relevant to this article was reported.

\section{Ethical approval}

This study was approved by ethics committee of the Shahid Beheshti University of Medical Sciences (IRB No. REC.0313). All procedures performed in studies involving human participants were in accordance with the ethical standards of the institutional and/or national research committee and with the 1964 Helsinki declaration and its later amendments or comparable ethical standards.

\section{Patient consent}

Verbal consent was obtained by phone from all individual participants included in the study.

\section{References}

1. Hamza HS, Gaber KR, Raouf WA, Dohain AM, Mohsen GSA, Elfattah ANA, et al. Fetal echocardiography for early detection of conotruncal anomalies in high risk pregnancies: one year follow-up. J Clin Neonatol 2016;5:35.

2. Stubblefield PG, Carr-Ellis S, Borgatta L. Methods for induced abortion. Obstet Gynecol 2004;104:174-85.

3. Özden S, Delikara MN, Avci A, Fiçicioglu C. Intravaginal misoprostol vs. expectant management in premature rupture of membranes with low Bishop scores at term. Int J Gynaecol Obstet 2002;77:109-15.

4. Trussell J, Guthrie K. Choosing a contraceptive: efficacy, safety, and personal considerations. In: Hatcher RA, Trussell J, Nelson AL, Cates W, Stewart FH, Kowal D, editors. Contraceptive technology. 19th revised ed. New York (NY): Ardent Media, Inc.; 2007. p.19-47.

5. Lalitkumar S, Bygdeman M, Gemzell-Danielsson K. Midtrimester induced abortion: a review. Hum Reprod Update 2007;13:37-52.

6. Walters KM, Simon RA, Woessner KM, Wineinger NE,
White AA. Effect of misoprostol on patients with aspirinexacerbated respiratory disease undergoing aspirin challenge and desensitization. Ann Allergy Asthma Immunol 2017; 119:71-6.

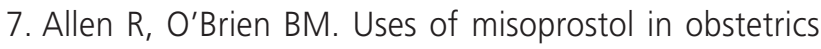
and gynecology. Rev Obstet Gynecol 2009;2:159-68.

8. Stephenson ML, Wing DA. Misoprostol for induction of labor. Semin Perinatol 2015;39:459-62.

9. Grady K, Johnston T. Maternal collapse, including massive obstetric haemorrhage, amniotic fluid embolism and cardiac arrest. In: MacLennan K, O'Brien K, MacNab WR, editors. Core topics in obstetric anaesthesia. Cambridge: Cambridge University Press; 2015. p.191.

10. Green L, Knight M, Seeney FM, Hopkinson C, Collins PW, Collis RE, et al. The epidemiology and outcomes of women with postpartum haemorrhage requiring massive transfusion with eight or more units of red cells: a national cross-sectional study. BJOG 2016;123:2164-70.

11. Nankali $A$, Jalilian $N$, Keshavarzi $F$, Rezaei $R$, Rezaei $M$. Comparison of efficacy and side effects of different administration routes of misoprostol (oral, vaginal, and sublingual) for second-trimester abortion. Int J Pediatr 2017; 5:5887-95.

12. Ercan Ö, Köstü B, Özer A, Serin S, Bakacak M. Misoprostol versus misoprostol and foley catheter combination in 2nd trimester pregnancy terminations. J Matern Fetal Neonatal Med 2016;29:2810-2.

13. Daskalakis GJ, Mesogitis SA, Papantoniou NE, Moulopoulos GG, Papapanagiotou AA, Antsaklis AJ. Misoprostol for second trimester pregnancy termination in women with prior caesarean section. BJOG 2005;112:97-9.

14. Cuellar Torriente M, Steinberg WJ, Joubert G. Misoprostol use for second-trimester termination of pregnancy among women with one or more previous cesarean deliveries. Int J Gynaecol Obstet 2017;138:23-7.

15. Cunningham FG, Leveno KJ, Bloom SL, Spong CY, Dashe JS, Hoffman BL, et al. Williams obstetrics. 25th ed. New York (NY): McGraw Hill Professional; 2018.

16. Munro MG, Mainor N, Basu R, Brisinger M, Barreda L. Oral medroxyprogesterone acetate and combination oral contraceptives for acute uterine bleeding: a randomized controlled trial. Obstet Gynecol 2006;108:924-9.

17. World Health Organization. Health worker role in providing safe abortion care and post abortion contraception. Geneva: World Health Organization; 2015. 


\section{Obstetrics \& Gynecology Science}

Marzieh Jamali, et al. Misoprostol and maternal complications

18. Borgatta L, French A, Vragovic O, Burnhill MS. Early medical abortion with methotrexate and misoprostol: outcomes and satisfaction among women aged 15-21 years. J Pediatr Adolesc Gynecol 2001;14:9-16.

19. Zikopoulos KA, Papanikolaou EG, Kalantaridou SN, Tsanadis GD, Plachouras NI, Dalkalitsis NA, et al. Early pregnancy termination with vaginal misoprostol before and after 42 days gestation. Hum Reprod 2002;17:3079-83.

20. Marwah S, Gupta S, Batra NP, Bhasin V, Sarna V, Kaur N. A comparative study to evaluate the efficacy of vaginal vs oral prostaglandin E1 analogue (misoprostol) in management of first trimester missed abortion. J Clin Diagn Res 2016;10:QC14-8.

21. Nath J, Jain M, Najam R, Sharma R. To compare the effectiveness and tolerability of misoprostol as a cervical ripening agent in the first trimester abortion through sublingual and vaginal routes of administration. Bangladesh J Obstet Gynaecol 2016;27:63-6.

22. Küçükgöz Güleç U, Urunsak IF, Eser E, Guzel AB,
Ozgunen FT, Evruke IC, et al. Misoprostol for midtrimester termination of pregnancy in women with 1 or more prior cesarean deliveries. Int J Gynaecol Obstet 2013;120:85-7.

23. Naguib AH, Morsi HM, Borg TF, Fayed ST, Hemeda HM. Vaginal misoprostol for second-trimester pregnancy termination after one previous cesarean delivery. Int J Gynaecol Obstet 2010;108:48-51.

24. Karaçor T, Yalınkaya A, Görük N, Özler A, Turgut A. Misoprostol-induced termination of secondtrimester pregnancy in women with a history of cesarean section: a retrospective analysis of 56 cases. Ginekol Pol 2013;84.

25. Dickinson JE, Evans SF. The optimization of intravaginal misoprostol dosing schedules in second-trimester pregnancy termination. Am J Obstet Gynecol 2002;186:470-4.

26. Iftikhar R, Burney WA. Role of misoprostol in inducing abortion in previous cesarean section. J Surg Pak 2009;14:3. 